\begin{tabular}{|c|c|c|c|c|c|}
\hline 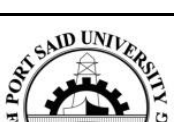 & \multicolumn{4}{|c|}{$\begin{array}{l}\text { PORT SAID ENGINEERING RESEARCH JOURNAL } \\
\text { Faculty of Engineering - Port Said University }\end{array}$} & \\
\hline 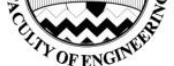 & Volume 18 & No. 1 & March 2014 & pp: 79 - 89 & \\
\hline
\end{tabular}

\title{
EFFECT OF TIN CONTENT AND ECAP PASSES ON THE MECHANICAL PROPERTIES OF Cu/Sn ALLOYS AS BEARING MATERIALS
}

\author{
Elshafey.A. Gadallah ${ }^{1}$, Mohamed.A. Ghanem ${ }^{2}$, Mohamed.Abd El-Hamid ${ }^{3}$, and Ahmed.E. El-Nikhaily ${ }^{4}$
}

\begin{abstract}
Equal channel angular pressing (ECAP) is a materials processing method that allows very high strains to be imposed, leading to extreme work hardening and microstructure refinement. Cast $\mathrm{Cu}-2,5$ and $10 \mathrm{wt} \% \mathrm{Sn}$ alloys in the form of $25 \mathrm{~mm}$ diameter and $300 \mathrm{~mm}$ long rods are ECAPed through $12 \mathrm{~mm}$ diameter, $120^{\circ}$ inner angle, and $20^{\circ}$ out arc angle die. It is possible to ECAP those alloys for 5, 4, and 1 pass at room temperature, respectively. Grain size decreases of with increasing Sn content and number of ECAP passes. Besides, the ultimate tensile stress, proof strength, and hardness of $\mathrm{Cu}-2,5$ and $10 \%$ Sn alloys increase with Sn content and ECAP pass number. However, UTS of $2 \%$ Sn alloy reaches a maximum value after 4 passes, and that of 5\% Sn alloy reaches its maximum after 3 passes. Moreover, the elongation percent decreases strongly after first ECAP pass. The elongation of $\mathrm{Cu}-2$ and $5 \% \mathrm{Sn}$ alloys begin to increase after second pass until third and fifth passes, respectively. On the other hand, the wear resistance is improved by increasing Sn content and number of ECAP pass, especially after first pass. Also, remarkable decrease is observed in surface roughness (Ra) by decre asing Sn content and by increasing the number of ECAP pass.
\end{abstract}

Key words: Cu/Sn alloys, Microstructure, Mechanical properties and Wear resistance.

\section{Introduction}

In the past few years, the use of bronze as a bearing material is very popular among researchers. Copper and copper alloys have been extensively used in many fields as bearing, bush, sleeve and so on, due to their good corrosion resistance, excellent thermal and electrical conductivity, self-lubrication property, and wear resistance [1-9]. Nanometer or sub micrometer grain size, due to severe plastic deformation, has received great interest in the last decade, because of unusual mechanical and physical properties and high performance [10,12]. Severe plastic deformation (SPD) is an important way to obtain high strength and fine grains of an alloy.

Many plastic deformation processes have been developed to enhance mechanical properties of an alloy using simple shear. It was reported [13] that, significant grain refinement occurred by applying ECAE, which increased the alloy strength. Major grain refinement and Hall-Petch strengthening can be achieved in bulk billets through severe plastic deformation. Thus a work piece is subjected to cold or warm processing to very large strains. As a result, ultra-fine grain structure with grain size of several tens or a few hundreds of nanometres is produced [14]. Equal channel angular pressing (ECAP) is considered

1M.Sc. Student, Faculty of Industrial Education, Suez University. 2Lecturer, Mechanical Dept., Faculty of Industrial Education, Suez University. 3Professor, Mechanical Design \& Prod. Dept., Faculty of Engineering, Zagazig University. 4Professor, Mechanical Dept., Faculty of Industrial Education, Suez University. the most popular SPD process. The principle of ECAP was discussed earlier $[15,16]$. Copper alloy containing $~ 38 \%$ $\mathrm{Zn}$ and $\sim 3 \%$ Sn was subjected to ECAP at $400^{\circ} \mathrm{C}$ [17]. The evolved microstructures were non homogeneous with areas of both recrystallized and unrecrystallized grains. The average grain size within the re-crystallized areas was $\sim 1.5 \mu \mathrm{m}$ [17]. Recently, Wang et al. [18-21] studied the tensile behavior of an ECAP deformed $\mathrm{Cu}-\mathrm{Cr}$ alloy. Also, the effect of a second phase and the ECAE number of passes on the hardness of $\mathrm{Cu}-10 \% \mathrm{Al}-4 \% \mathrm{Fe}$ cast alloy was studied. It was observed that, the grain size decreased gradually with increasing pass number. The hardness and strength increased, considerably, as a result of grain refinement and dislocation strengthening after ECAE [22].

Wear properties of engineering materials have significant effects on the serviceability and durability [23]. It is generally known that, the wear resistance of metals and alloys is proportional to their hardness. Enhancement of the wear resistance of materials can be attained by various methods as heat treatment and surface coating.

Relatively light weight $\mathrm{Cu}-10 \% \mathrm{Al}-4 \% \mathrm{Fe}$ alloys are superior substitutes for other metallic materials in many applications. Reduction in weight contributes to reducing energy consumption. [23, 24]. Copper based tin bronzes are used as bearing materials with high wear resistance. Friction and wear properties of these materials can be improved by adding tin. Tin bronze $(90 \% \mathrm{Cu}-10 \% \mathrm{Sn})$ is the most suitable bearing material under corrosive conditions, at high temperatures and high loads. Recently, Wang et al. [25] studied surface roughness of $\mathrm{Cu}-\mathrm{Sn}$ and 
$\mathrm{Cu}-\mathrm{Zn}$ alloys before and after wear testing. They observed a decrease of surface roughness of pure $\mathrm{Sn}, \mathrm{CuSn} 10$, and $\mathrm{CuZn} 30$ alloys. Surface roughness of pure $\mathrm{Cu}$ and pure $\mathrm{Zn}$ bearings increased after wear tests because of soft phase properties.

In the present work, the effects of Sn content (up to 10wt.\%) of $\mathrm{Cu}-\mathrm{Sn}$ alloys, and number of ECAP passes on tensile properties, hardness, wear resistance, and surface roughness are investigated.

\section{Experimental work}

The alloys, with chemical compositions listed in Table1, are prepared in a graphite crucible furnace by melting suitable proportions of copper and other elements to obtain $2.5 \mathrm{~kg}$ of the required alloy at $1200^{\circ} \mathrm{C}$ for $2 \mathrm{~h}$. The molten alloy is then poured in a sand mould to form $25 \mathrm{~mm}$ diameter and $300 \mathrm{~mm}$ long bars. Stirring is performed during the melting to be sure of the dissolution of commercial pure tin in copper. The molten alloy is then left $25 \mathrm{~min}$. for natural cooling. Then, the sand mold is opened and the product is machined to the required dimensions for ECAP (12 $\mathrm{mm}$ in diameter and $86 \mathrm{~mm}$ long).

A split die is so designed that ECAP is carried out and repeated quickly and easily. The die is $12 \mathrm{~mm}$ diameter, $120^{\circ}$ inner angle $(\Phi)$, and $20^{\circ}$ out arc angle $(\Psi)$, as shown in Fig.1. The samples are well lubricated with greased graphite. Then, ECAP is performed at room temperature on $\mathrm{Cu}-2,5$ and $10 \mathrm{wt} \% \mathrm{Sn}$ alloys, up to 5 passes.

Microstructure study is carried out using Olympus optical microscope, on cross sections cut perpendicular to the pressing direction, at bar midpoint, before and after ECAP of $10 \mathrm{~mm}$ diameter and $15 \mathrm{~mm}$ long bars. Cross section grinding is performed using SiC papers up to 1200 mish size at $500 \mathrm{rpm}$ rotation speed. Prior to polishing, the samples are rinsed with ethanol and then polishing is performed with a $0.05 \mu \mathrm{m}$ alumina emulsion. Metallographic surfaces are chemically etched in acetic picric solution $\left(2 \mathrm{~g} \mathrm{~K}_{2} \mathrm{Cr}_{2} \mathrm{O}_{7}, 8 \mathrm{~mL} \mathrm{H}_{2} \mathrm{SO}_{4}, 4 \mathrm{~mL}\right.$ saturated $\mathrm{NaCl}$ solution, $100 \mathrm{~mL} \mathrm{H} \mathrm{H}_{2} \mathrm{O}$ ) for $90-120 \mathrm{sec}$ [26].

Vickers hardness tests are carried out on ground and polished surfaces. Each value is the average of at least five readings. All measurements are taken using an applied load of $0.5 \mathrm{Kg}$, and dwell time of $15 \mathrm{sec}$ before and after ECAP by using Vickers hardness tester Model-HWDV-7S.

Tensile specimens $6.5 \mathrm{~mm}$ in diameter and $26 \mathrm{~mm}$ gauge length, Fig.1b, are machined from ECAPed samples. The axis of tensile test specimen is parallel to ECAP pressing direction. Tensile testing is conducted up to failure at room temperature using (ASTM standard E8M-03). Tensile tests were carried out using the universal testing machine, Instron model (4208-002), operated at constant strain rate of $0.050 \mathrm{~mm} / \mathrm{sec}$. The test is repeated three times for each condition, in order to calculate average values.

Table 1: Chemical composition of the alloys (wt.\%).

\begin{tabular}{|l|c|c|c|c|c|c|c|c|c|c|}
\hline Alloy Content Wt.\% & Cu & Sn & Zn & Pb & Fe & Ni & Al & Mn & Si & P \\
\hline Cu-Sn 2 & 97.55 & 2.025 & 0.319 & 0.108 & 0.03 & 0.00 & 0.04 & 0.009 & 0.00 & 0.01 \\
\hline $\mathrm{Cu}-S n 5$ & 93.51 & 4.960 & 0.200 & 0.075 & 0.04 & 0.17 & 0.06 & 0.003 & 0.00 & 0.00 \\
\hline $\mathrm{Cu}-\mathrm{Sn} 10$ & 89.48 & 9.713 & 0.346 & 0.202 & 0.03 & 0.18 & 0.04 & 0.018 & 0.00 & 0.02 \\
\hline
\end{tabular}

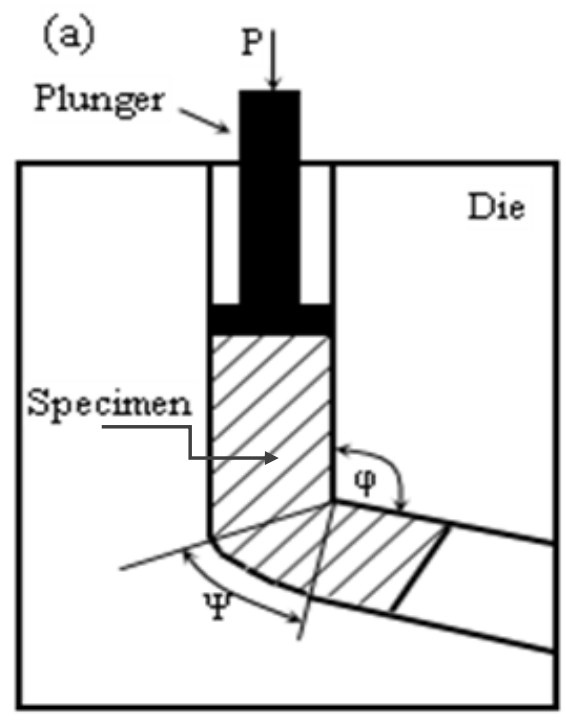

(Dimension mm)

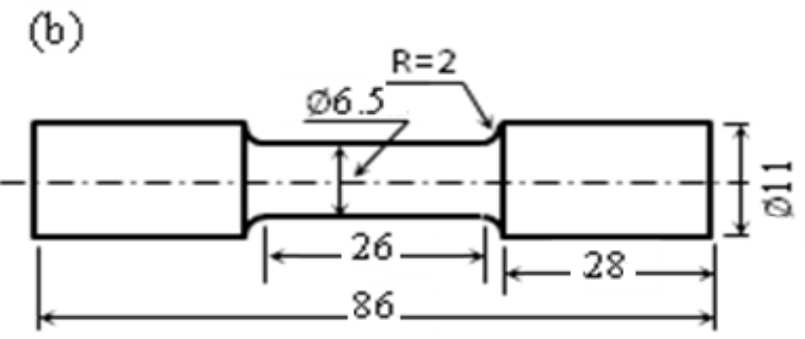

Figure (1), Schematic illustration of a) Equal channel angular pressing (ECAP) die, and b) Tensile test specimen. 
Dry sliding wear tests are conducted using TNO Tribometer-block-on-ring wear test machine, as shown in Fig.2. The test specimen is $8 \mathrm{~mm}$ diameter, and $12 \mathrm{~mm}$ long, with its axis parallel to the pressing direction, and is machined from the sample center before and after ECAP. The wear test is performed at room temperature $\left(20 \pm 5^{\circ} \mathrm{C}\right)$ and $50 \pm 5 \%$ humidity conditions. The rotating sliding ring (carrier), made of tool steel, is $73 \mathrm{~mm}$ diameter, with hardness of $63 \mathrm{Rc}$. The test is performed at $450 \mathrm{rpm}$ for $20 \mathrm{~min}$.
Two different loads of 50 and $70 \mathrm{~N}$ were applied in order to investigate the effect of the load on the wear rate. Thorough cleaning of samples is carried out with acetone prior to and after testing, and dried in hot air. Cleaned samples are weighed on a microbalance, and the wear rate is computed by the weight loss technique. Finally, surface roughness $(\mathrm{Ra})$ prior to and after wear testing of present alloys $\mathrm{Cu}-2,5$, and $10 \mathrm{wt} . \% \mathrm{Sn}$, measured using Mitutoyo.5J-201 test rig. The wear rate at any condition is the average of five tests.

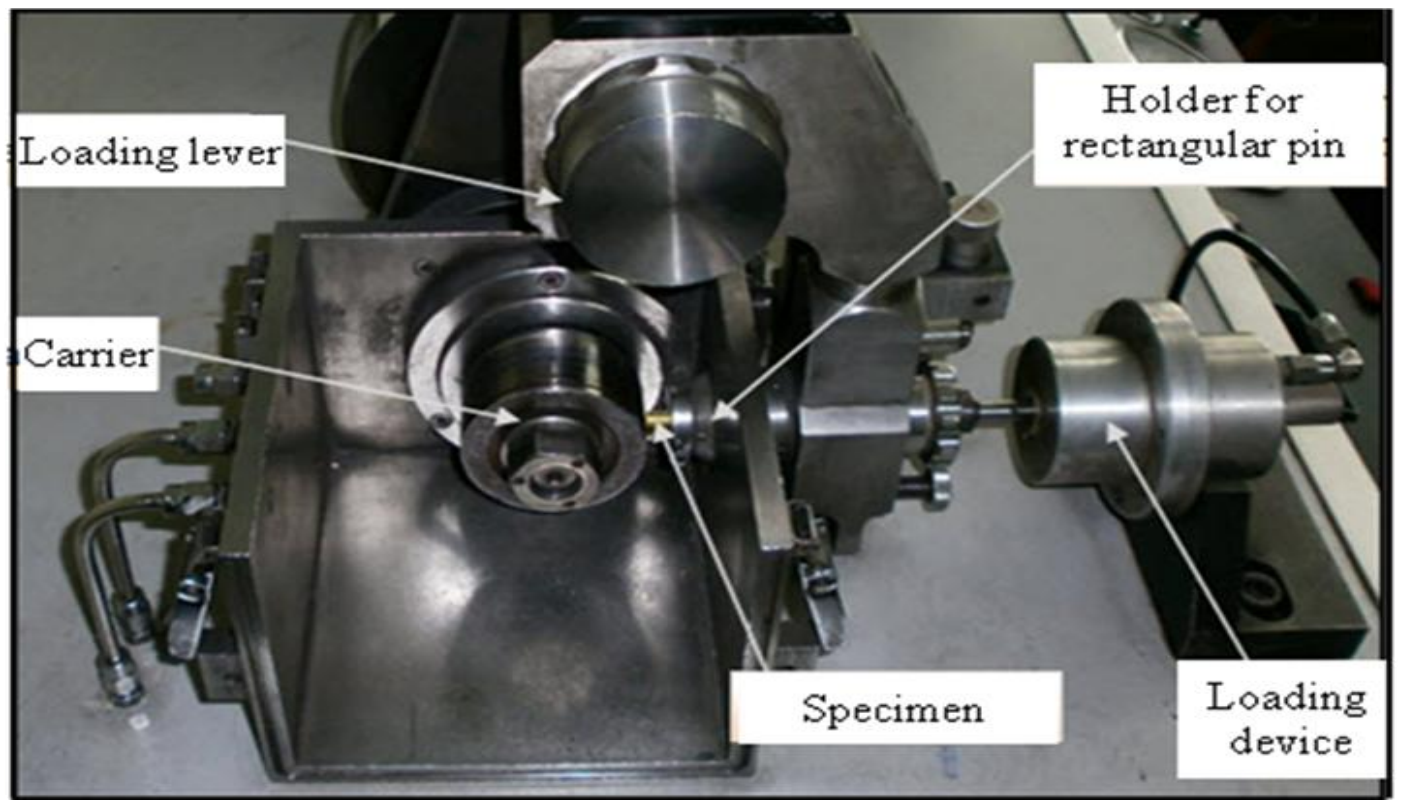

Figure (2), Wear machine (block-on-ring test rig), model TON Tribometer.

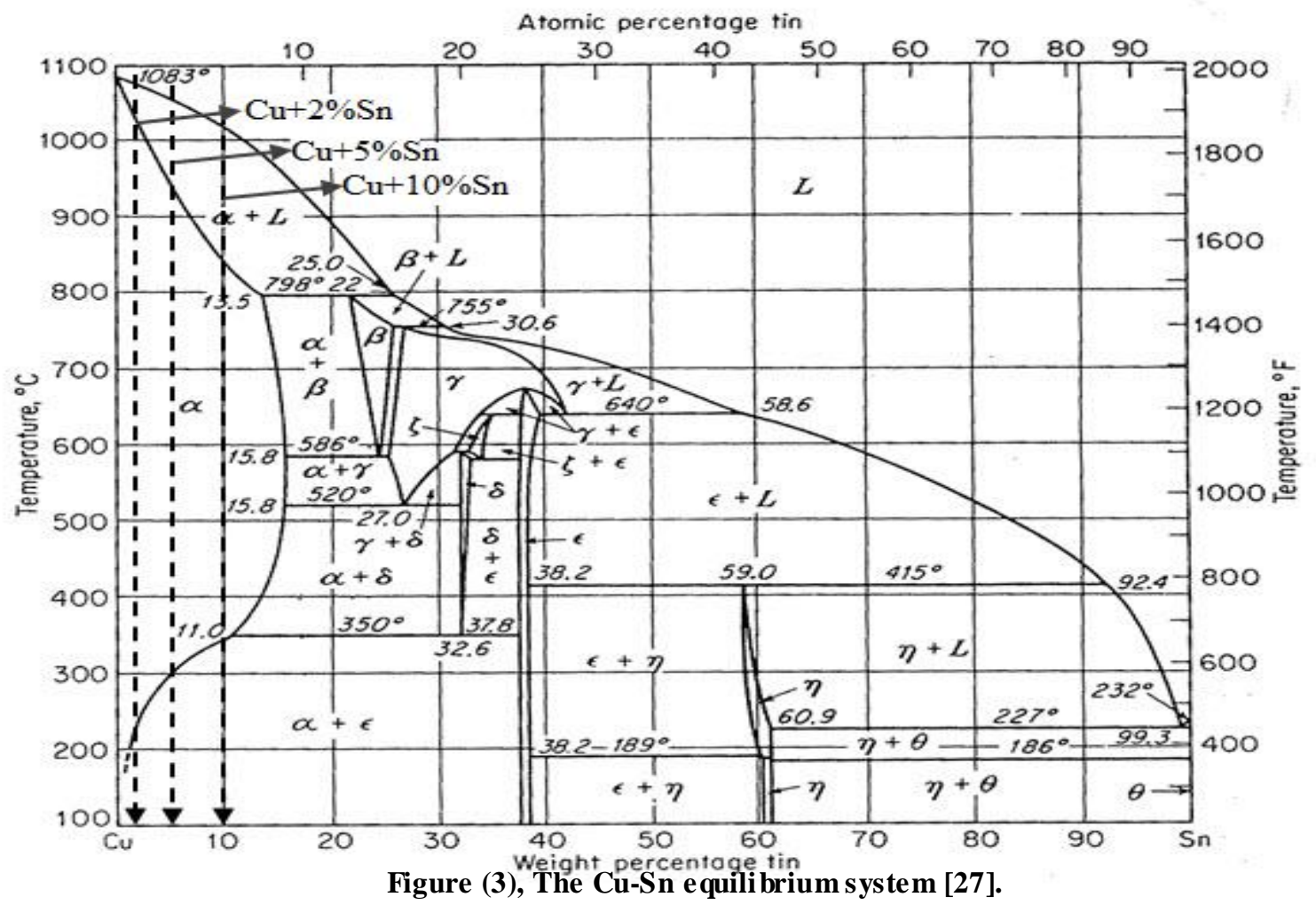




\section{Results and discussion}

\section{Microstructure Analysis}

Figure (3) represents the phase diagram of the $\mathrm{Cu}-\mathrm{Sn}$ system [27]. Present alloys $(\mathrm{Cu}-2 \% \mathrm{Sn}, \mathrm{Cu}-5 \% \mathrm{Sn}, \mathrm{Cu}-$ $10 \% \mathrm{Sn}$ ) are also indicated on the figure. Based on the phase diagram the present alloys, at room temperature, consist of $\mathrm{Cu}$ solid solution containing about $2 \mathrm{wt} . \% \mathrm{Sn}$, and precipitates of $\mathrm{Cu}_{3} \mathrm{Sn}$ intermetallic, which contains $38.37 \%$ Sn.
The microstructure of $\mathrm{Cu}-2 \% \mathrm{Sn}$ alloy is shown in Fig.4. Without ECAP Fig.4(a) it consists mainly of equi-axed grains of $\mathrm{Cu}$ solid solution containing about $2 \% \mathrm{Sn}$. The microstructure after one to five ECAP passes is shown in Fig.4b to Fig.4f, respectively. With increasing the number of ECAP pass, the fraction of elongated grain structure decreases, the distortion becomes more uniform, and the structure is refined. It is observed in Fig.4(f), that the structure is homogeneous, and the grain size is significantly refined.
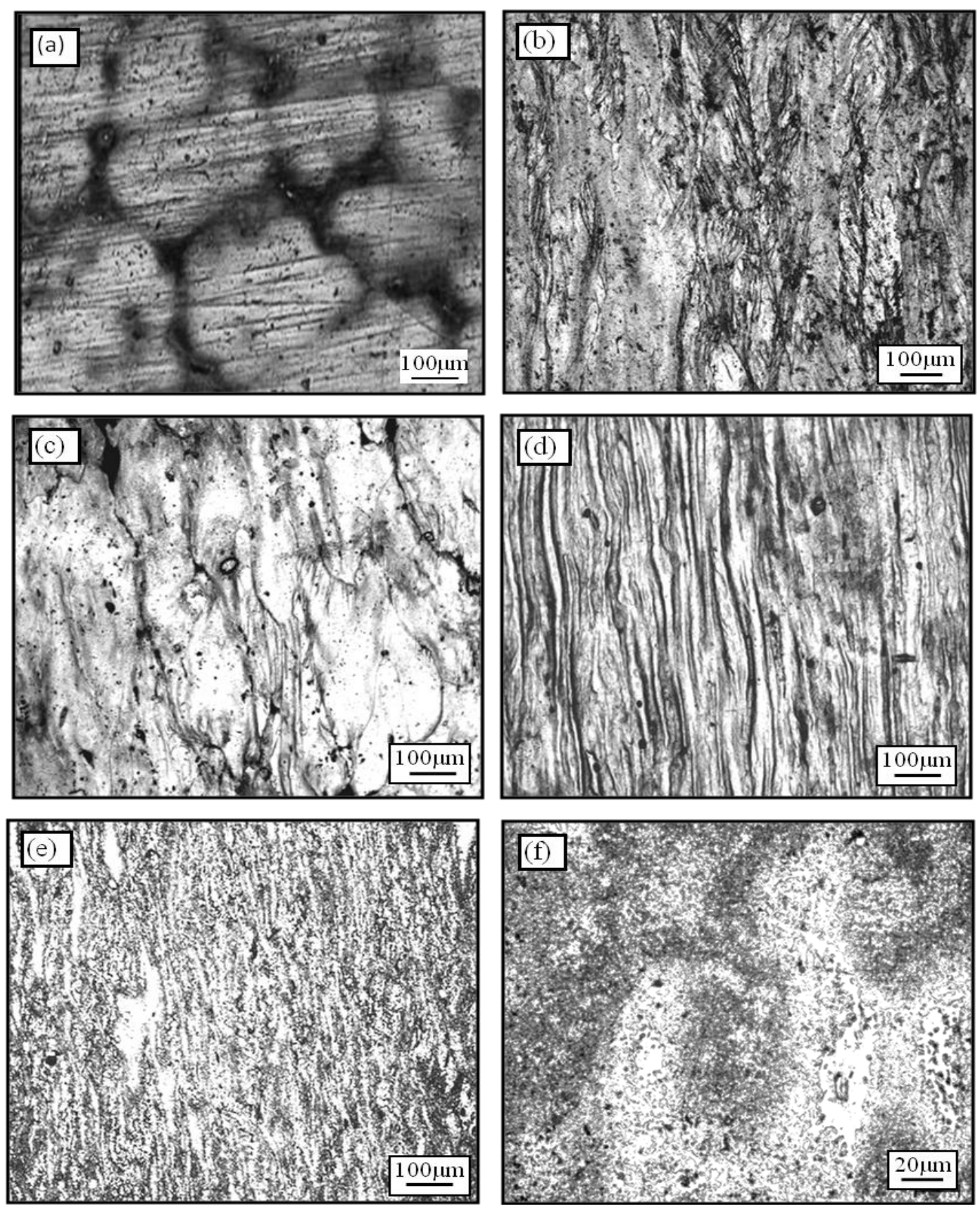

Figure (4), Microstructure of $\mathrm{Cu}-2 \%$ Sn alloy: a) before ECAP, b) after one ECAP pass, c) after 2

ECAP passes, d) after 3 ECAP passes, e) after 4 ECAP passes, and f) after 5 ECAP passes. 
The microstructure of $\mathrm{Cu}-5 \% \mathrm{Sn}$ alloy is shown in Fig.5. It is obvious that before starting ECAP passes the grain structure is no more equi-axed and tends to be dendritic. On the basis of the phase diagram in Fig.(3), it consists of $(\mathrm{Cu})$ containing about $2 \% \mathrm{Sn}$, and about 8.5 wt.\% Cu3Sn precipitates, located mainly at grain boundaries, Fig.5(a). After the first ECAP pass, the grain size is strongly refined and the dendritic structure becomes more pronounced, Fig.5(b). After 2 and 3 passes Fig.5(c) and Fig.5(d ) the grains are elongated in the pressing direction, and the structure is more refined. After four passes the structure becomes homogeneous, and the grain size is significantly refined, Fig.4(e).

Figure (6) demonstrates the microstructure of the $\mathrm{Cu}$ $10 \%$ Sn alloy. According to Fig.(3), and before ECAP the alloy consists of about $22 \mathrm{wt} . \% \mathrm{Cu} 3 \mathrm{Sn}$ precipitated around dendrites of $(\mathrm{Cu})$ containing about $2 \% \mathrm{Sn}$ After one pass, the structure is significantly refined, and the precipitates are aligned parallel to the pressing direction.
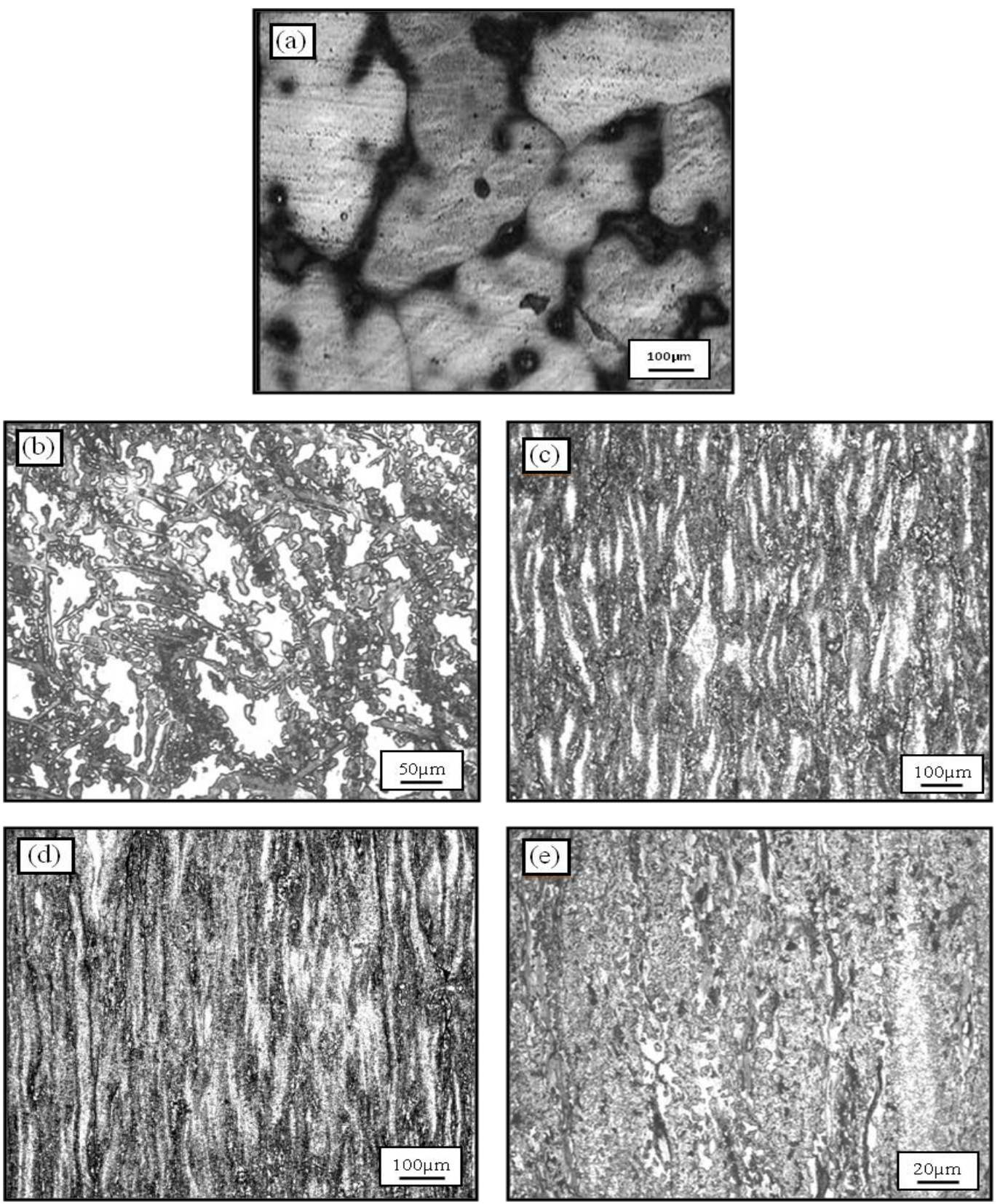

Figure (5), Microstructure of Cu-5\% Sn alloy; (a) before ECAP, (b) after one ECAP pass, (c) after 2 passes, (d) after 3 passes, and (e) after 4 passes. 

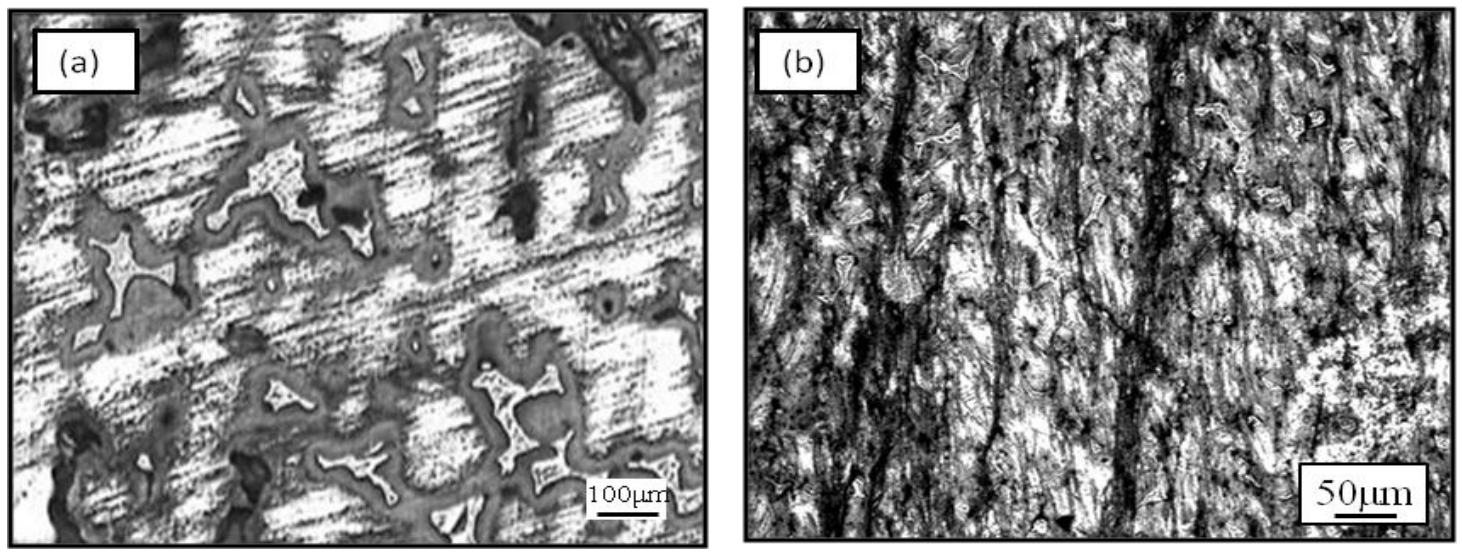

Figure (6), Microstructure of Cu-10\% Sn alloy; (a) before ECAP, and (b) after one pass.

In general, it could be noted that, the dendritic structure becomes more pronounced at higher $\mathrm{Sn}$ contents. Also, increasing the number of ECAP passes greatly refines the evolved microstructure. However, increasing $\mathrm{Sn}$ content of $\mathrm{Cu}-\mathrm{Sn}$ alloys limits the possible number of ECAP passes, which leads to a defect free product. At $10 \%$ Sn only one pass is possible.

\section{Mechanical Properties}

Figure (7) shows the tensile engineering stress-strain curves of present $\mathrm{Cu}-\mathrm{Sn}$ alloys processed from zero to five ECAP passes.

The effect of Sn content and number of ECAP passes on the hardness of present alloys is shown in Fig.8. Before ECAP processing, tin content has a strong effect on hardness. VHN of $\mathrm{Cu}-10 \% \mathrm{Sn}$ is 277 , while that of $\mathrm{Cu}-2 \% \mathrm{Sn}$ is only 102. After the first ECAP pass the hardness of $\mathrm{Cu}-2 \% \mathrm{Sn}$ alloy increases from 102 to 184, while that of $\mathrm{Cu}-5 \% \mathrm{Sn}$ alloy increases from 124 to 229 , and that of $\mathrm{Cu}-10 \% \mathrm{Sn}$ alloy increases from 277 to 297 . In all cases, the hardness increases with successive ECAP passes, so that after the maximum possible number of passes, VHN is about 300.

The tensile properties, including proof strength $\sigma_{0.2 \%}$, ultimate tensile stress (UTS), elongation percent, and hardness of present $\mathrm{Cu}-\mathrm{Sn}$ alloys without ECAP processing and after various number of ECAP passes are summarized in Table 2.

The effect of Sn content and number of ECAP passes on the tensile properties of $\mathrm{Cu}-\mathrm{Sn}$ alloys is shown in Fig.9. and table 2. Without ECAP processing UTS of present alloys is not much affected with increasing $\mathrm{Sn}$ content from 2 to $10 \%$. Values of UTS increase rapidly after first ECAP pass, but with a higher rate at a higher $\mathrm{Sn}$ content. Then, with more passes UTS of $\mathrm{Cu}-\mathrm{Sn}$ alloys continues to increase with a lower rate reaching values of $838.95,847.99$, and $646.83 \mathrm{MPa}$ for $2 \% \mathrm{Sn}(5$ passes), 5\% Sn (4 passes), and $10 \% \mathrm{Sn}$ (one pass), respectively. The proof stress exhibits a similar behavior, as shown in Fig.9. This may be explained in view of precipitation, work, and grain boundary strengthening mechanisms. Similar behavior was observed in previous work $[20,21]$.

Table 2: Tensile properties of present $\mathrm{Cu}-\mathrm{Sn}$ alloys before and after ECAP processing.

\begin{tabular}{|c|c|c|c|c|c|c|c|}
\hline \multirow{2}{*}{ Alloy } & \multirow{2}{*}{$\begin{array}{c}\text { Mechanical } \\
\text { property }\end{array}$} & \multicolumn{6}{|c|}{ Number of ECAP passes } \\
\hline & & $\mathbf{0}$ & 1 & 2 & 3 & 4 & 5 \\
\hline \multirow{4}{*}{$\mathrm{Cu}-2 \% \mathrm{Sn}$} & $\sigma_{0.2 \%}, \mathrm{MPa}$ & 129.35 & 220.80 & 279.50 & 304.64 & 348.15 & 405.11 \\
\hline & UTS, MPa & 234.12 & 388.23 & 552.39 & 671.21 & 829.34 & 838.95 \\
\hline & Elongation, $\%$ & 22.179 & 11.585 & 12.571 & 13.199 & 13.528 & 13.995 \\
\hline & Hardness (VH) & 102.32 & 183.98 & 222.96 & 255.06 & 276.58 & 316.9 \\
\hline \multirow{4}{*}{$\mathrm{Cu}-5 \% \mathrm{Sn}$} & $\sigma_{0.2 \%}, \mathrm{MPa}$ & 146.69 & 250.16 & 296.43 & 327.04 & 385.79 & - \\
\hline & UTS, MPa & 243.43 & 528.12 & 740.32 & 847.99 & 842.84 & - \\
\hline & Elongation, $\%$ & 21.156 & 10.781 & 11.421 & 12.798 & 12.596 & - \\
\hline & Hardness (VH) & 123.6 & 228.62 & 261.92 & 283.56 & 308.92 & - \\
\hline \multirow{4}{*}{$\mathrm{Cu}-10 \% \mathrm{Sn}$} & $\sigma_{0.2 \%}, \mathrm{MPa}$ & 172.31 & 342.37 & - & - & - & - \\
\hline & UTS, MPa & 252.52 & 646.83 & - & - & - & - \\
\hline & Elongation, $\%$ & 18.29 & 9.026 & - & - & - & - \\
\hline & Hardness (VH) & 276.78 & 297.16 & - & - & - & - \\
\hline
\end{tabular}



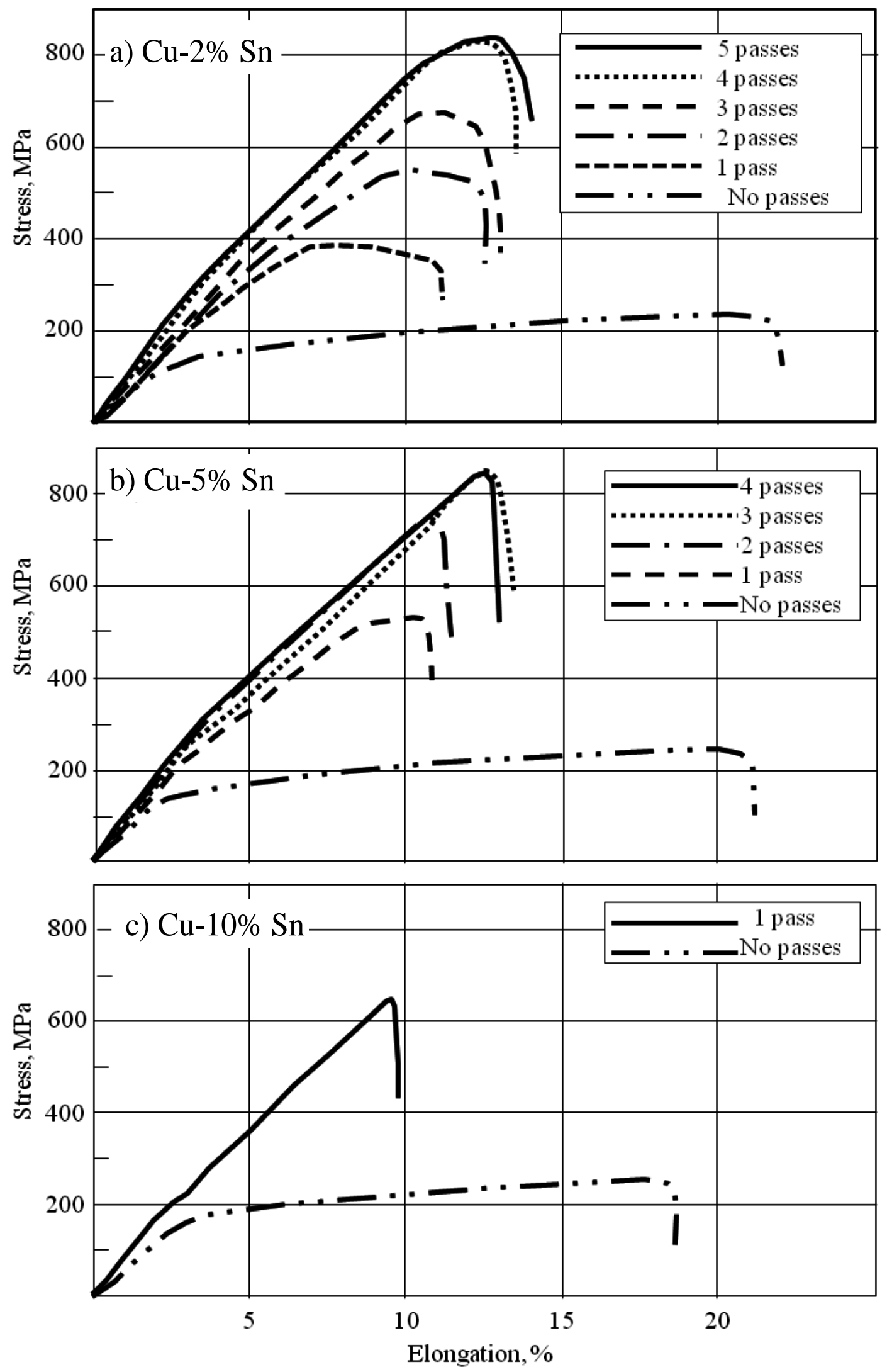

Figure (7), Tensile engineering stress-strain curves of present $\mathrm{Cu}-\mathrm{Sn}$ alloys before and after ECAP passes. 


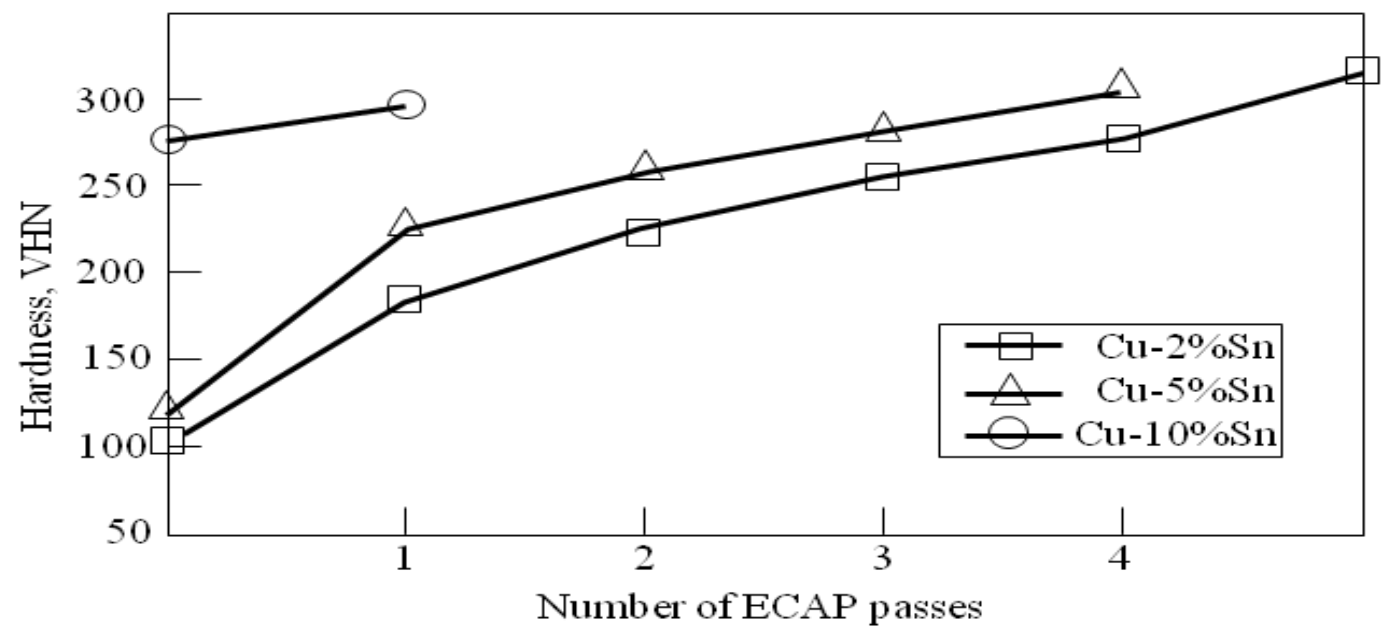

Figure (8), Hardness of present Cu-Sn alloys before and after ECAP passes.
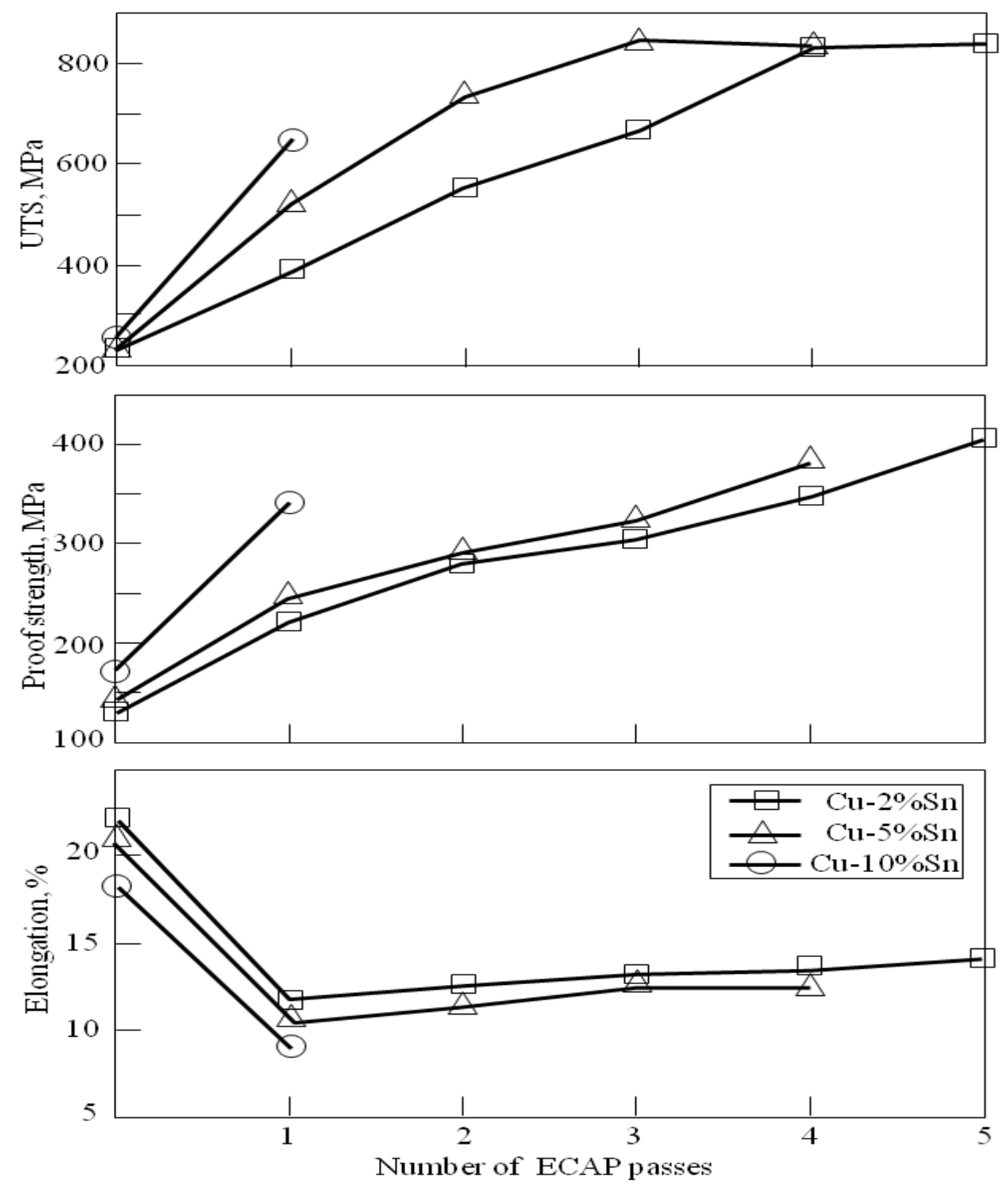

Figure (9), Ultimate tensile strength, proof strength, and el ong ation percent of $\mathrm{Cu}$-Sn alloys before and after ECAP processing. 
Table 3: Surface roughness of Cu-Sn alloys subjected to various number of ECAP passes.

\begin{tabular}{|c|l|c|c|c|c|c|c|}
\hline \multirow{2}{*}{ Alloy } & \multicolumn{6}{|c|}{ Surface Roughness Ra, $\boldsymbol{\mu m}$, after various ECAP number of passes } \\
\cline { 3 - 8 } \multicolumn{2}{|c|}{} & $\mathbf{0}$ & $\mathbf{1}$ & $\mathbf{2}$ & $\mathbf{3}$ & $\mathbf{4}$ & $\mathbf{5}$ \\
\hline \multirow{2}{*}{$\mathrm{Cu}-2 \%$ Sn } & Before wear & 0.69 & 0.61 & 0.49 & 0.45 & 0.44 & 0.42 \\
& After wear & 0.62 & 0.47 & 0.42 & 0.28 & 0.275 & 0.27 \\
\hline \multirow{2}{*}{$\mathrm{Cu}-5 \%$ Sn } & Before wear & 0.72 & 0.67 & 0.63 & 0.45 & 0.44 & - \\
& After wear & 0.70 & 0.26 & 0.22 & 0.20 & 0.13 & - \\
\hline \multirow{2}{*}{$\mathrm{Cu}-10 \%$ Sn } & Before wear & 1.64 & 1.35 & - & - & - & - \\
& After wear & 1.02 & 0.34 & - & - & - & - \\
\hline
\end{tabular}

Without ECAP processing, the elongation of present $\mathrm{Cu}-\mathrm{Sn}$ alloys decreases to 22.2, 21.2 and 18.3\%, with increasing $\mathrm{Sn}$ content to 2,5 and $10 \%$, respectively as shown in Fig.9. Then, after first ECAP pass, the elongation decreases significantly with almost the same slop to reach 11.6, 10.8, and $9 \%$. However, further increase of ECAP number of passes for $\mathrm{Cu}-2$ and $5 \% \mathrm{Sn}$ alloys slightly increases elongation percent at almost a constant slop, so that the elongation of $\mathrm{Cu}-2 \% \mathrm{Sn}$ is $14 \%$ after 5 passes, and that of $\mathrm{Cu}-5 \% \mathrm{Sn}$ is $12.6 \%$ after 4 passes.

Moreover, the wear rate of present $\mathrm{Cu}-\mathrm{Sn}$ alloys is determined using a block-on-ring test rig. The obtained results at a speed of $450 \mathrm{rpm}$, and under loads of 50 and $70 \mathrm{~N}$ are shown in Fig.10, which shows the effect of $\mathrm{Sn}$ content and number of ECAP passes on the wear rate. It could be observed that the wear rate decreases with increasing the number of ECAP passes, specially the first passes. On the other hand, the wear rate decreases also with the increase of Sn content. Furthermore, the applied load strongly affects the wear rate, specially at lower Sn content.

To check the possibility of applying ECAP processing to obtain a finished product, surface roughness before and after wear testing is measured for ECAP specimens of present $\mathrm{Cu}-\mathrm{Sn}$ alloys, as shown in Table 3. It is clear that, the surface roughness of present $\mathrm{Cu}-\mathrm{Sn}$ alloys without ECAP processing increases with $\mathrm{Sn}$ content specially at higher Sn content (10\%), which may arise due to the presence of a higher volume fraction of brittle precipitates of $\mathrm{Cu} 3 \mathrm{Sn}$ intermetallic. After wear test, surface roughness tends to decrease, specially at $10 \%$ $\mathrm{Sn}$. By applying ECAP, the surface roughness decreases with the increase of ECAP pass number, and appreciably decreases after wear testing. Such observations make the present alloys suitable for being used as bearing materials.

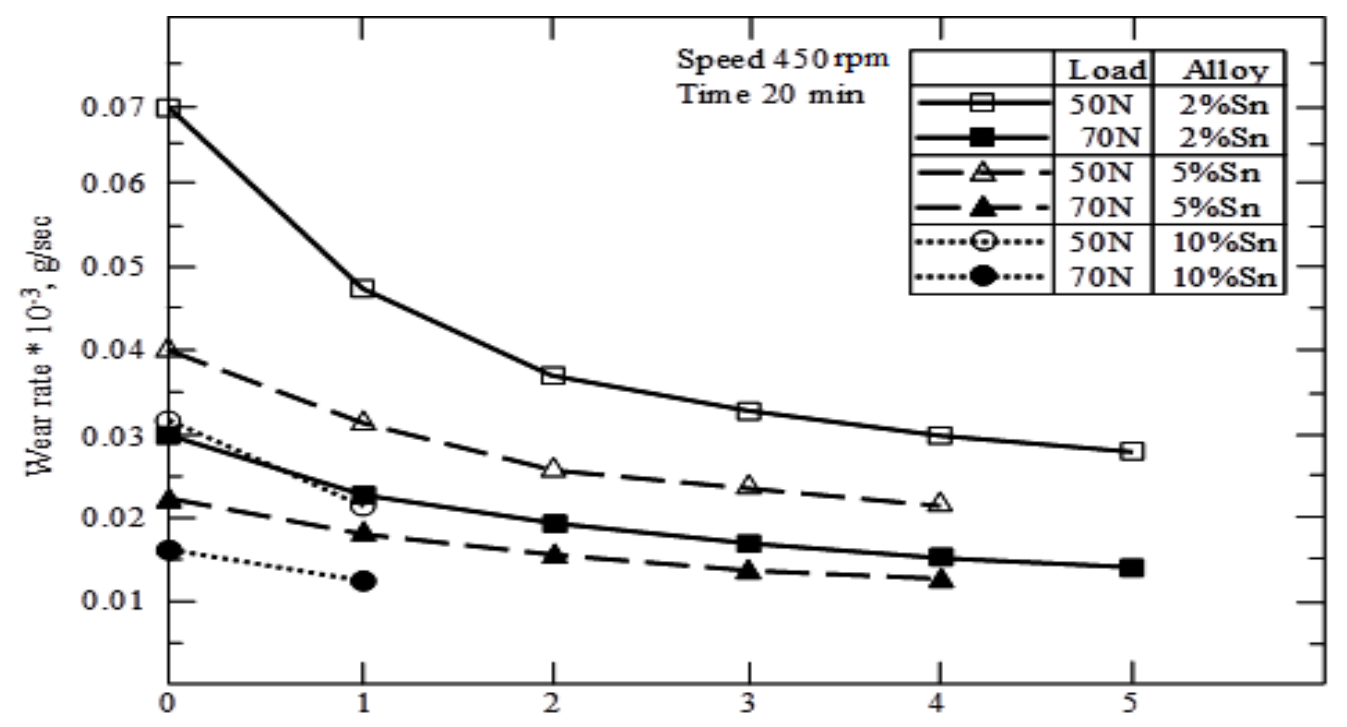

Figure (10), The effect of ECAP number ofupassescinfassicontentson the wear rate of $\mathrm{Cu}-2,5$ and $10 \%$ Sn alloys under the various applied loads. 